\title{
Narrative Shifts: Race, Culture, and the Production of Screendance
}

Marcus White, Arizona State University and Moving 24fps

keywords: screendance, production, video, film, dance, race, intersectionality, gender

I am a curator and maker of screendance. I enjoy working with other makers of screendance. This essay is a snapshot of several years building relationships with film and dance makers in the production of this type of work. It is through those experiences that I see issues of race and representation in screendance in diverse spaces and places. From Europe to the United States, museum curated to home screenings, Blockbusterstyle to indie small budget - creating equitable professional standards conscious of race and more importantly intersectionality is the 'key frame' of this essay.

Moving 24fps is a platform founded by Carlos Funn and me, where teams of one professional dance maker and one filmmaker are paired to create work in a single weekend. These 'creatives' make work as a part of the touring Festival: to date, it is the only project of its kind in the United States. It focuses exclusively on the production of screendance and is situated within various 'partner cities.' The goals of the project within a given city include: 1 . foster a community of creatives who may have never worked together; 2 . bolster the creative marketplace for high quality screendance work in the United States; 3 . present a platform where equitable and inclusive storytelling is embedded inside the infrastructure of the experience. We intentionally selected cities outside of the mega markets for dance and film such as New York and Los Angeles. The two cities that I will highlight in this essay are Phoenix and Detroit. These cities have distinct histories with systems of oppression inside of the larger frame of the United States politic. We wanted to learn from creatives in these cities about race, gender, and politically charged image making. More specifically, we were curious how screendance can be used as a tool to help reimagine each city's narrative related to identity politics and what these stories could reveal about a national discourse of race and culture within the production of screendance. In this way, this underscores what critical dance studies scholar Melissa Blanco Borelli refers to as the function of film and dance "as productions for the socio-historical moment in which they develop." ${ }^{\prime \prime}$

Part of the impetus for the project was rooted in early conversations about the public discourse in US-based mass media that spectacularizes black and brown bodies. The mediated narratives of these bodies through film, television, and social media created

The International Journal of Screendance 9 (2018). 
a flood of viscerally irresponsible image-making rooted in stereotypes of quasi-minstrel presentation interlaced with trauma, grief, and death of the black and brown body. Diamond Reynolds' patient filming of her boyfriend, Philando Castile's murder by a Minneapolis police officer is exemplary. ${ }^{2}$ We also see the male body displayed alongside substantial text and interviews that are rooted in racialized histories and ideology that frame whole communities of people as thugs, comedic relief, "drug dealers, criminals, and rapists." ${ }^{\prime 3}$ Moreover, the appropriation of black and brown bodies and cultural capital vis-à-vis Miley Cyrus and her capitalizing on the black female posterior; ${ }^{4}$ Madonna and her adoption of vogue performance from the Xtravaganzas, ${ }^{5}$ or most recently Taylor Swift's ${ }^{6}$ white-washed adaptation of Beyoncé's Lemonade showcases White female "mainstream" artists and by extension mainstream society's obsession with black cultural products with little acknowledgment or citation to the makers or producers of these products.

These contemporary images, narratives, and representations are an extension of centuries of negotiating race and gender within dance and culture in the United States. These references and images serve as visual and political backdrops to illustrate the cultural context and time that birthed the Moving 24fps project. Positive representations of black and brown bodies seemed to be an essential and leading motivation of the project. However, once we began the process of vision planning and creating the project we uncovered a larger more poignant set of questions. We became less concerned about how hegemonic systems such as whiteness or racism construct, deconstruct, or borrow from representations of black and brown bodies ${ }^{8}$ as this repeats, realigns, and recenters power dynamics that could not capture the nuance of what was actually happening in the field during production of the Moving $24 \mathrm{fps}$ projects. We were more curious about who was crafting stories or visual culture with bodies of color and how race, culture, and identity were embedded inside the dance film ${ }^{9}$ production process including aesthetic choice making, creative collaborations, and the production of film/video in relationship to dance. ${ }^{10}$

\section{Method - Nuts and Bolts}

This provocation is informed by a collection of both informal and open forum interviews with over 25 creatives from across the country about their experience inside the Moving $24 \mathrm{fps}$ project. I conducted another round of interviews to zoom in on three creatives' processes as case studies. These case studies highlight particular aspects of the creatives process and I examine how by race, gender, and culture shape these dance shorts projects. For the purposes of this essay, I will use these case studies from the Moving 24fps iterations in Detroit, Michigan and Phoenix, Arizona to examine and situate screendance as a method to investigate representation, equity, and inclusion in screendance production. 
From those interviews, two questions emerged that help frame this essay:

- What considerations and choices do creatives consciously or inherently make to center race and regional geopolitics?

- How do the projects and collaborations create or promote equity in dance film curation and audience development within these regions?

We instinctively understood that different cities and regions had specific needs and histories connected to social movement building. For instance, Detroit's black-white relations as an extension of the civil rights era is a much different social and political climate than the Latinx LGB and trans undocumented individuals in Arizona. ${ }^{11}$ There are parallels that cut across these regions but there were also different needs to consider. This essay's scope and my position as an artist/scholar/curator zooms in on how these historically marginalized communities tell stories on their own behalf centering their own aesthetic values in the production of the work.

We selected creatives based on their body of work and their unique artistic lens informed by their identity and lived experience. In each city, the creatives met for the first time during a kick-off event at a local establishment where they planned their project from concept to post-production. They then had an entire weekend to craft a dance short to screen three days later. The pressure-cooker situation compelled them to immediately "trust their instincts"12 and to create with a new collaborator quickly. Their process was informed by prompts that we as curators selected. The creatives used these prompts in addition to their own interests to highlight, promote, and engage their process around particular themes and pressing issues of our time.

We noticed individuals centered their perspectives and worldview inspired by the prompts. In the pressure cooker of a weekend, creatives had little time to second-guess their own assumptions, aesthetic choices, or heavily critique their decisions. The prompts we crafted differed in each city. For example, in Detroit, we selected keywords from a transcript from our director's meeting minutes: "Listen," "Care," "Joy," and "Unravel." These words were an extension of our meeting about how we saw the potential of screendance as a strategy to understand and promote humanity within a highly volatile socio-political climate. These words were pulled from that transcript and taken out of context where creatives randomly selected one of those words from an envelope at the kick-off event and used these words as a springboard for their creative process. These prompts energized and inspired creatives to tap into their own experiences and relationship to the words in collaboration with another person they did not know. These conversations, dialogues, and creative processes are among the highlights of the project.

The case studies within this provocation highlight creatives' processes and analysis of screendance works through a cultural critique and dance studies lens. These case 
studies are not intended to be 'token' projects or exceptions; they simply are examples that we can pull from as models to demonstrate how race and culture may operate within particular contexts in the production of screendance. Moreover, not all racially marginalized groups are represented in this essay. This provocation is simply a snapshot of the project and is not intended to be a comprehensive blueprint about how to think, produce, or curate screendance. Instead, this is a recounting and analysis of the process and select projects produced during the weekend with the goal of opening up a conversation about how race and culture operate in the production of screendance in specific US cities.

\section{Case Study \#1: Black Feminist Craft in Dance Filmmaking}

During our proof of concept phase, we positioned Detroit, Michigan as our initial city to engage the project. This choice made sense logistically as I have had long-standing relationships in the city. The city is a culturally fertile ground as evidenced by decades of producing arts and culture, chiefly the development of MoTown and the Techno sound. This fertile ground is also challenged by a whole set of historical consequences, which are compellingly told in the text "The Origins of Urban Crisis" whose historical depth spans beyond the scope of this essay. It is important to know that Detroit is a chocolate city. ${ }^{13} 83 \%$ of the population is African-American and over $1 / 3$ of households are under the poverty line. ${ }^{14}$ This post-industrial city is still grappling with the realities and echoes of a destabilizing socio-economic climate largely developed in the latter half of the 20th century with the collapse of the American auto and manufacturing industries. The shift from Detroit as the car making mecca, racially contentious policy, along with transition of the tax base and economic power created a perfect storm for the decline of the city in the 20th century. As a result, the population decreased considerably, crime increased, and the city was fighting to recharge the financial base it had lost. Today, particular segments of the city are becoming economic epicenters that uphold the values of a growing city yet simultaneously displaces generations of black and brown families from their homes of almost a century. This is the economic and political reality of the city, which serves as the landscape for the project "Listen" developed by Ryan Kerr and Jennifer Harge.

Ryan Kerr self-identifies as a white male collaborating with Jennifer Harge, an AfricanAmerican female maker deeply rooted in Detroit and Highland Park. ${ }^{15}$ In our interview, Harge recalls how the prompt they received for the project "Listen" helped inspire a process featuring the act of listening as the key element in the production of the work. She recounts how quiet the shoots were with little to no background sounds with the exception of the natural environment. This created a sense of tranquility and peace for her as a dance maker. Her body responded to that energy in relationship to the camera often avoiding direct eye contact with the camera while remaining in "her world." 
She also mentions that, as a Black female dance maker, this was one of the few times where she felt heard by a white male as embodied by her collaborator. She mentions how her partner Ryan Kerr was an astute listener and responded in a way that disrupted her initial apprehension of working collaboratively with him. This rupture allowed her to move and navigate the space as the primary voice of the project. As the director, she was able to foreground her Black feminist perspective. She mentioned leaning in on Ryan's expertise as a filmmaker where he was able to make choices that amplified her voice and body's presence on the screen. For instance, Harge drew on large swooping action inspired by the concept of 'play' and black girl gestural vocabulary. Kerr listened to Harge's motivations and intention and used his skillset to create a sense of drama and attentiveness to detail in his cinematic approach to the work. The camera surveyed the body and acted more as a voyeur than active participant in the world created within the collaboration. They worked together to strategize how best to represent her body, voice, and perspective in relationship to the sites they selected.

A key component of the project is that we asked creatives to be responsive to the sites they selected and to choose sites that were unique to their region. The creatives investigated the depth, scale, and contributions of their sites in the creative process. The body, camera, and site were used to re-frame their personal relationship to the city and its narrative. In this work, Harge's solo body is captured in three main sites: green spaces on Belle Isle, a well-known recreational and tourist attraction in post-bankruptcy Detroit; ${ }^{16}$ her grandmother's basement; and an open field in her predominantly AfricanAmerican Highland Park neighborhood.

As a maker, Harge recognizes that, for many viewers, the film is the entry point to her creative work including her alter ego, JJ LOVE. JJ dons a blonde wig, trench coat, and appears as the sole human subject in the film. Prior to this project, $\mathrm{JJ}$ and Harge had always "co-existed" in live performance where Harge would transition in and out of performative states of $\mathrm{JJ}$ and herself. In our interview, she mentions how the film "Listen" is the first time JJ makes her first solo appearance without the presence of the maker and primary architect. Harge mentions witnessing her own body through the archive of film and how this transformed her own understanding of the potential of her alter ego to "live" beyond Jennifer's own body. As JJ, her alter ego, Harge is able to witness her own body as a type of archive that comments and critiques race, gender, and desire. She mentions that some people may assume that $\mathrm{J}$ is an attempt to create or imitate "whiteness" through the specific cultural marker of the blonde wig that covers her face for the majority of the short.

Upon deeper investigation, Harge actually positions JJ within the larger framework of African-American women's/femme ${ }^{17}$ experiences of participating and going to Black hair care businesses, beauty supply stores, and salons in Detroit and Highland Park. JJ not only functions as a metaphor and embodied representation of Black women's/femme engagement with these industries but, more importantly, JJ 
demonstrates the power of Black femme/women as creative imaginators. The wig and her screen presence create a fantastical being, one that shows how a black woman can try on external parts such as wigs in an attempt to reimagine self. Harge mentions how this body on screen explores the edges of this fantasy in experimentation and play. She continues to state in our interview that looking at the film with some distance allows her to see the reality that Black women/femme have very few opportunities to express fantasy and joy in public sites such as a park or open field. She mentions how her fantasy is often policed in expected and unexpected places such as her experiences on Belle Isle. The film operates as an archive that captures this fantasy and places the site of Detroit as a space of escapism. This challenges the narrative of Detroit as empty, desolate, or struggling, allowing the individual and spectator to enter the site as a space of fantasy, play, and exploration.

$\mathrm{JJ}$ 's/Harge's black body amongst the natural environment positions a different narrative about these spaces. She springs from one foot to another inside an abandoned caboose covered in graffiti art that has weathered the test of time. The caboose serves as a bridge between two green pastures where the camera shifts our point of view in relationship to her body. The camera always serves as an outsider to the solo dancer's pleasure. We see jump cuts between her negotiating the space of the caboose and playing the piano in the large grassy field.

She mentioned that this open and public space, however, left her feeling exposed or vulnerable in a way that simply did not exist in the comfort of her grandmother's basement-a site she knew intimately and felt as her home place. ${ }^{18}$ The basement was a space she frequented regularly as she conducts day-to-day mundane tasks. It largely served as a space to pass through. For this project, the process of filming allowed her to activate this space and to see the space as a site of creation. Ryan Kerr brought in practicals (i.e., Christmas lights) to illuminate the space, the body, and the everyday objects that were in the basement including a tiny piano, which appears throughout the short. The collaborative filmmaking process allowed Harge and Kerr to see the potential of the everyday sites as spaces for visual storytelling and, more importantly, to imagine pleasure.

The final images capture the dancer performing large-scale swooping movement in super slow motion. These expansive movements have a sense of liberation and joy. The camera captures her expressivity and allows the viewer to see the dancer claim the physical space around her as a space of freedom. This joy and work was distinctly contemporary and distinctly black. Black joy serves as a metaphor to reframe this site and to re-envision the post-industrial city. Detroit is just one of many stories in the Rust Belt within the American Midwest. ${ }^{19}$ In this moment, we see what McKee tells us is the promise of good storytelling: the discovery of "life, its pains and joys, at levels and in directions you have never imagined. ${ }^{20}$ Screendance, in this instance, helps expand our notion of what is possible in space and time. 
Watch: "Listen" (2016). Co-Directors: Jennifer Harge and Ryan Kerr. Performance and Movement: Jennifer Harge. Film/Video: Ryan Kerr. Shot on location in Detroit and Highland Park.

https://www.youtube.com/watch?time_continue=69\&v=leX66EpWyY0

\section{Case Study \#2: Indigenous Aesthetics to Challenge Assumptions of Nationhood in the US}

In Phoenix, we wanted to learn more about the unique presence of racial and ethnic minorities and cultures beyond the densely Black urban spaces such as Detroit. We were confronted with the realities of how to honor and ethically uphold the rich cultural traditions and values of the region of the Southwest as it relates to race, culture, and the production of screendance. We invited Indigenous Enterprise to be a part of the Moving 24fps: Phoenix iteration. The cultural advocacy group is comprised of Indigenous people of the Navajo nation. The group is located in the urban center of Phoenix and negotiates the successes and challenges balancing traditional values of the reservation with the realities of living, creating, and working in the sixth largest urban center in the US. The group infuses hip-hop and traditional Navajo dances to promote their cause. In Phoenix, creative teams were given the prompt "Phoenix" - the Greek mythological creature of regeneration. ${ }^{21}$ We wanted the creatives to connect to the city's namesake and to incorporate the idea of "rebirth" inside their choreographic and cinematic choice making. The creatives were also given a natural element such as wind, water, air, fire, and metal. Indigenous Enterprise randomly selected "water" and had to incorporate "rebirth" as the creative impetus for their project.

The group of six male dancers were inspired to use the traditional water warrior dances of the Navajo Nation as a movement point of reference. ${ }^{22}$ The group's leader Kenneth Shirley, who is also a filmmaker, was interested in how to capture and best position the indigenous bodies on the camera to highlight the strength and vitality of the dancers while also increasing awareness of water as a precious resource within his communities.

The dance and film drew on an embedded indigenous aesthetic practice in the development of the short. According to indigenous scholar Steve Leuthold, ${ }^{23}$ indigenous aesthetic refers to key concepts across multiple indigenous groups that bind these communities together including self-determination, cultural continuity, cultural distinctiveness, and most importantly, attachment to place. These points are a critical means to understand Indigenous Enterprise's creative decisions and aesthetic values in the creation of this project. Shirley, who directed and edited the film, along with dancers from the troupe, and videographer Kyler Litson, shot the short at the Pueblo Grande Museum and Archeological Park as a part of the Annual Indian Market, a gathering of several indigenous nations. This archaeological site was once inhabited by the Hohokam people and is the largest preserved archaeological site in the city of 
Phoenix and includes indigenous arts, galleries, and replicated houses from the Hohokam. Once a bastion of culture and life for these people, it is now, many years later, the site and container for the dance film created. The site serves as background and offers a sense of legacy; however, I would be remiss if I did not distinguish the cultures of the Hohokam and the Navajo dances referenced in the film.

Using the element of water as a point of inspiration has a sense of irony within the context of a desert, which largely has limited access to water. The dancers had few opportunities to access physical bodies of water, but were expected to demonstrate water in their project. The dancers used their water warrior dances as mode of expression within the film. The use of slow motion in the dance film highlights details such as the frill of the traditional dress and the thunderous beat of the footwork pumping vibrations through the body. The ability to slow the motion of the action allows the viewer to witness a flow of movement that parallels the flow of water. The film suspends time and allows the viewer to witness flow and command of the body.

The background included audio speakers, POW-MIA Flags, portable restrooms, food stands, and a predominantly, though not exclusively, white audience. Having visited the site before and after the performance I had a chance to chat and engage with these audience members who attended this event as a cultural experience. The camera captures the performance of the dancers and the audience who are additional subjects in the film. They are both watching and being watched. They watch and capture the performance of the dance on their mobile phones and the viewer of the film observes the audience watching the dance, creating multiple layers of seeing and being seen through the medium of screendance. This spectacle within the frame of a screendance project produces different meanings about how the dance is read in the particular context of a Indigenous "market." Indigenous Enterprise mentions how these dances have culturally specific meanings particularly when performed within native-centered spaces and ritual places. Shirley also mentions the importance of building cultural understanding for non-Native audiences. His group's mission is to educate audiences about these dances in various spaces and to increase awareness of the dance and culture. He saw the Moving $24 \mathrm{fps}$ project as a way to bridge his two passions, dance and film, and to expand the reach of his indigenous culture to a wider audience.

The film ends with a slate that conjures Standing Rock along with the hashtags \#NoDAPL and \#WaterisLife. This reference serves as a call to action for the viewer and places dance filmmaking as a political act. The slate is in direct response to the actions and policies enacted by the US government that directly impact federally recognized tribes in the Dakotas. ${ }^{24}$ This call to action unites indigenous communities around the central themes in indigenous aesthetic practices most specifically natural resources and connection to the land. The Dakota Access Pipeline (DAPL) is an underground oil pipeline within the Dakota region of the US. In Winter 2016/17, this project gained national attention due to the legal ramifications and impact on the Sioux nation and 
Lake Oahe, the primary water reservoir for the reservation. This policy would violate preexisting tribal treaty rights and complicate notions of tribal sovereignty within the US.

The use of social media hashtags increases the level of virality and connection to a larger online movement. When connected to the dance film and shared online it offers wide scale distribution of their work and the justice movement more broadly. The final slate and the dances presented remind the viewer of the socio-political complexities that exist and complicates our notion of what constitutes an American or US nationalist politic via screendance. This reveals the opportunity of screendance to reignite conversations about federally recognized tribes, government policy, race and culture. More importantly it is an opportunity to ask more complicated questions rooted in nationhood, sovereignty, and defining an 'American' aesthetic within dance film.

\section{Watch: “Untitled” (2017). Director: Kenneth Shirley. Director of Photography: Kyler Litson. Performance: Indigenous Enterprise https://www.youtube.com/watch?v=p1kW-97Wbxg}

\section{Case Study \#3: Cross-Cultural Limits in Urban Spaces in the US}

Mary "Mama" Ar-Rasheed is a Cambodian-American Muslim B-girl ${ }^{25}$ who calls Detroit home. During her process in creating 'resolute' with DMV ${ }^{26}$ artist $C$. Funn she was faced with many challenges related to her identity as a B-girl. At the time, she had recently injured herself during a battle, and talked about how this prevented her from being able to execute movement distinct to her style, specifically floor work, freezes, and power moves. These moves demanded the engagement of particular parts of her body she simply could not access because of this prolonged injury. This situation compelled her to share her emotional journey inside the biopic style dance film. Her story was recorded and her voice serves as narration in the project.

Shot at night on the street corners of Detroit, the work opens with hand gesticulations. She sourced these movements from her study of waacking as a direct result of her inability to "hit the floor"27 as a B-girl. The close ups during this opening montage style action sequence accompanied by a trap beat, captures the mood, and presence of her Asian body. The first few images capture her face in relationship to her dynamic and dexterous hand dances. In our interview, she mentions how these hand motions incorporate Apsara ${ }^{28}$ gesticulations as performed by the Royal Ballet of Cambodia. This traditional dance is her link with her own cultural upbringing and serves as an entry point to her distinct style of waacking, a form that highlights the dexterity, strengthen and control of the arms and hands. As Cambodian-American, her body maintains a cultural memory as a part of an Asian diaspora within the context of a predominantly African-American post-industrial US-based urban center. Her body simultaneously exists within a metaphysical and cultural space of US and Cambodia. When asked where 
she learned Apsara dances, she mentions pockets of time and people introducing her to the form at gatherings such as the Cambodian New Year celebrations or social parties. She stated that she would learn the movements through observation. These gatherings were a part of her upbringing in the US and helped her connect to her Southeast Asian heritage. Her body demonstrates an in-between - a cultural liminality where she negotiates her understanding of US and Cambodian culture. This is further complicated when she mentions her development as a K-Pop vocalist. ${ }^{29}$ She situates her Asian-ness within the US, Korea, and Cambodia simultaneously. Yet, her "global" body also exists within a liminal space of racial constructions in the context of Detroit, US.

In our interview, I asked her how race showed up for her in "resolute." She clearly mentions how she understands black Americans' contributions and creation of hip-hop and street forms in the US, which she began to learn and perfect in the late 1990s and early 2000s. She also mentioned her mission to learn, engage community, and share knowledge in a way that supports the culture and honor the legacies of the creators. Implicitly, Mama negotiates Blackness and Asianness on camera as a part of the production process. Her fashion reflects an African-American urban sensibility as she wears a black shirt captioned "do what is right, not what is easy" in large font. She also dons a black snapback ${ }^{30}$ with the iconic Detroit city logo positioned in place of the ' $D$ ' of the word-"HARDCORE." This word is the logo for her crew Hardcore Detroit-the most popular street dance crew in the region. Her dress signifies a particular type of Blackness rooted in urban and street culture. At the same time she wears a red veil with harem pants, signifying in some ways Asianness more specifically rooted in colonialist conceptions of the "Orient.."31 Her movement flows between waacking, ${ }^{32}$ Apsara gestures, and breakin' vocabularies. The confluence of these forms allows her to find physical pleasure, a place to belong. This then helps her connect to her dance community, cultural past, and present position within the city's predominantly innercity Black community. ${ }^{33}$

The centering of the dancers of color with the backdrop of an urban horizon opens up opportunities about how we understand the power of the marked body on camera. The project intentionally centers bodies that traditionally have not been seen or valued within the current curatorial and production practice of screendance. As curators of this project, we offer a wide range of 'visual politics' that supports screendance maker, curator, and scholar Cara Hagan's claim that screendance's default is to represent "largely Western, white, and college educated" ${ }^{34}$ movers on screen.

Rosenberg makes mention of the various genres and subgenres of film and movement in his writing on "Evacuating Genre." In this work, he expresses the need to value screendance work both within the meta-narrative of the work and the meta-knowledge that informs the work including cultural assumptions, artistic predecessors, and how the medium of screendance constantly straddles the visual cultures and rules within dance and film. He attempts to break up formalism as a frame of reference to view 
screendance work. Though he does not expressly mention the role and presence of hiphop or urban as subgenre, I would like to suggest that, perhaps in the case of "resolute," urbanism or an urban aesthetic practice could shift how we think about screendance practice and visual politics. In this instance, I refer to urban aesthetic ${ }^{35}$ as an aesthetic rooted in legacies created in urban spaces in post-civil rights era United States. Through this lens, we can situate the work of Danny Hoch and his hip-hop manifesto that articulates the practice of graffiti, MC, breakin' (dance), and DJ-ing as having distinct aesthetic value. This is not to suggest that we cannot apply the suggestions in Rosenberg's work and dance filmmaking techniques holistically when capturing urban dance. In fact, I think they are directly applicable. I do though want to suggest that perhaps there is an urban visual politics influenced by inner-city Black and Brown makers that impact how one produces dance film. It is through these forms where we see the artist and art making reclaim space within urban blight and understand the public space as visual canvas. In "resolute," we witness examples of this as we see the dancer and the camera capture and move alongside graffiti in public spaces and abandoned lots while also framing the body from worm's eye view with skyscrapers positioned in the background. The soundtrack created by D-the-Cypher references and sources trap techniques inside the track to support the narrative and text. In this short, we see the confluence of race, culture, and geography embedded within the styles of dance and the dance short.

Watch: "resolute" (2016). Co-Directors: Mary "Mama" Ar-Rasheed and C. Funn. Performance and Movement: Mary "Mama" Ar-Rasheed. Film/Video:

C. Funn. https://www.youtube.com/watch?v=rLe_xyzXfPU

\section{Changing the Visual Politic - Understanding the Screendance Consumer}

It was important that creatives who participated included a representative cross-section of communities within the region where we were hosting the event. The particular case studies in this essay center creatives of color in order to amplify their stories, bodies, and perspectives as a central component in the making of work. These projects also exist within particular social and political movements where creatives leverage their skills to respond to current cultural themes.

The presence of "skinned representation" as exampled by these case studies brought up other questions relating to identity politics. Intersectionality was a current that existed in all of these cases. It was difficult for us to separate racial representation for the screen and the invisibility or hyper visibility of particular bodies. In Detroit, the centrality of the woman's body in front of the camera revealed the reality of a marketplace and availability of particular dancers or dance makers in the specific region. This in and of itself is not a negative but does bring up questions about how gender and race intersect in representation for the camera. Moreover, where are the female filmmakers? In the examples provided in this essay, the woman's body was subjected to the gaze of the 
male filmmaker. Regardless of how "progressive" these men were, this initial process uncovered some of the gaps within the project that reflects the larger field of dance filmmaking. This goes beyond a multicultural approach rooted in tokenism (i.e., one woman, one person of color, etc.) yet points to a more equitable framing of inclusion, specifically thinking about how life experiences as an artist and storyteller are informed by how one navigates through the world within their multiple identities. We have successfully made efforts to develop a representative cross-section of creatives and remain curious about what considerations other curators make to amplify diverse voices: the "queer" body as maker? The "differently abled" body? The "trans" body?

Beyond representation and production, we are also curious to know who is the audience for screendance? When we visited these cities, we noticed very few persons of color in the audience. There were people of color closely connected to the creatives, but overwhelmingly the audience who attended these screenings self-identified as white. This instinctively is not a bad thing but it does make us wonder where are the people of color in the WATCHING of screendance? This points to a much larger quagmire in the screendance economy and marketplace of how to get communities of color excited about this experimental approach to dance and film/video. How do we as curators engage people of color to be interested in both making and watching dance film? I will continue to grapple with these questions in order to discover new ways of engagement with intersectional perspectives, viewpoints, and practices.

\section{Biography}

Marcus White is an American movement maker, educator, community engagement advocate and cultural WERKer. He is the Founder and Creative Director of Detroit-based performance production company White Werx. One of the company's initiatives is Moving 24fps - a Festival co-created with Carlos Funn/Funn Foto - where film and dance makers make new work in a single weekend. Marcus' teaching and creative practice centers embodied performance as transformational and is informed by his experiences and embodied investigations of black social and contemporary dance. In 2016, he joined the faculty of Arizona State University where he serves as an Assistant Professor of Dance within the Herberger Institute for Design and the Arts. At ASU, his research and teaching infuses justice and equity within creative practices for dance in relationship to live theatre and film, personal movement practice in urban, social dance formations, and arts business/career development. Marcus earned his MFA from the University of Michigan where his research explored dance making for the camera to unpack themes of surveillance, desire, and hypervisibility. 
Email: marcus.r.white@asu.edu (ASU) info@theofficialmrw.com (White Werx) Website: https://www.theofficialmrw.com

\section{Notes}

${ }^{1}$ Borelli, "Introduction," 12. See also Borelli, "Screening Nationhood."

${ }^{2}$ See Smith, "Minnesota Officer Acquitted in Killing of Philando Castile." It should also be noted that a significant number of black cis and transgendered women are also victims of gun-involved incidents with the police that largely go uncovered by mainstream media at the scale of the Castile case.

${ }^{3}$ See "Drug Dealers, criminals, rapists."'

${ }^{4}$ See Duca, "The Miley Cyrus Twerking Backlash, for Idiots."

${ }^{5}$ See Lawrence, "A history of drag and vogue balls."

${ }^{6}$ See Gamp, "Lemonade and Minute Maid."

${ }^{7}$ For more about Lemonade, see https://www.beyonce.com/album/lemonade-visualalbum/

${ }^{8}$ In this case "black and brown" specifically is an attempt to draw links between the African/African-American, Indigenous, and Latinx experiences. Paul Ortiz makes a strong case about intersectional perspective, shared history and struggle in An African American and Latinx History of the US.

${ }^{9}$ For the purposes of this essay, I use screendance and dance film interchangeably.

${ }^{10}$ For the purposes of this essay-person of color refers to any historically marginalized group based on their race in the US context, which encompasses but is not limited to African/African-American, Latinx/a/o/Chicano, Arab/ArabAmerican/Middle Eastern, Asian/Asian-American (excluding Slavic countries), Native/Indigenous. This is a slippery area as race is socially-constructed within particular contexts and is culturally specific. This is the limitation and failure of the word "person of color" but is an attempt to create working language about how race operates in the US context.

${ }^{11}$ See Santiago, "Transgender and Undocumented Leader Fights for Rights," which positions the Arizona, US political climate as it relates to intersectional identity. 
${ }^{12}$ Faulkner, K. Quote from Moving 24fps focus group

${ }^{13}$ A colloquial term used by African-Americans to identify urban centers in the US with a predominantly black population. Black here is defined widely across the African diaspora.

${ }^{14}$ Data provided by US Census-State of Michigan

https://www.census.gov/quickfacts/fact/table/detroitcitymichigan/RHI805210

${ }^{15}$ A municipality adjacent to Detroit-griped with similar, and in some cases worse, economic and political conditions as an echo of the changes in the once-booming auto industry - which the region monopolized for a long time.

${ }^{16}$ Kerr and Harge, "Listen" from Moving 24fps Project date accessed April 2017 https://youtu.be/leX66EpWyY0?list=PLEbzIUa-QxQaDgQhFytqmYFFOE97V9SZc

${ }^{17}$ Femme-female figure cisgender, transgender, gender non-conforming experience-where one assumes the gender performance of femininity, which may be distinct from performance of woman.

${ }^{18}$ See hooks, "Homeplace."

${ }^{19}$ See Czerniak, Formerly Urban.

${ }^{20}$ McKee, Story, 236.

${ }^{21}$ There are many layers that I could unpack as it relates to the reference of Grecian definitions of the Phoenix and by extension Euro-centered models and philosophies, which expand the scope of this essay.

${ }^{22}$ Indigenous Enterprise as a part of Moving 24fps: https://youtu.be/p1 kW-97Wbxg December 2017 "Moving 24fps: Phoenix"Untitled" by Kenneth Shirley/Indigenous Enterprise.

${ }^{23}$ See Leuthold, Indigenous Aesthetics.

${ }^{24}$ More information about Standing Rock and the Dakota Access Pipeline can be found here: https://nycstandswithstandingrock.wordpress.com/standingrocksyllabus/

${ }^{25}$ break girl. Female/woman practitioner of breakin' a social dance that started in the Bronx in the 1970s and has garnered international reputation.

${ }^{26}$ Colloquial abbreviation for DC, Maryland, and Virginia.

27 "Hit the floor" is a social dance reference in which a dancer, particularly a break girl or break boy goes into a cypher/cipher and demonstrates their breakin' movement vocabulary and prowess. 
28 "Apsara" performed by Cambodian Royal Ballet

https://www.youtube.com/watch?v=Erbp1 Isk96M date accessed December 2017

${ }^{29}$ Korean popular music largely inspired by American hip-hop culture and music yet has developed as distinct to South Korean culture, context, and people.

${ }^{30} \mathrm{~A}$ large flat brim baseball cap with an adjustable strap comprised of two plastic pieces that snap together.

${ }^{31}$ See Said, Orientalism.

${ }^{32} \mathrm{~A}$ cultural product of LGB and trans black communities in California. Popularized by syndicated show "Soul Train," the form includes fast-paced arm movement initiated from the corps, high energy footwork, and a dynamic funk feeling to communicate an idea or mood.

${ }^{33}$ It should be noted that regions outside the city proper have large racial minorities that are not African-American including Arab-American (Dearborn), Asian-American (various pockets), and Latinx (Southwest Detroit).

${ }^{34}$ See Hagan, "Visual Politics in American Dance Film."

${ }^{35}$ Most street dance practitioners would define hip-hop as specific to breakin, graffiti, emcee, and dj as essential "starter" elements. Urban or street serves as a broader term to encompass various cultural formations forms that include and may exist alongside hip-hop culture.

\section{References}

Ar-Rasheed, Mary Mar and Funn, C. "resolute," 2016.

https://www.youtube.com/watch?v=rLe_xyzXfPU

Blanco Borelli, Melissa. "Introduction" and "Screening Nationhood" The Oxford Handbook of Dance and the Popular Screen. University of Oxford Press, 2014. 12-30. https://doi.org/10.1093/oxfordhb/9780199897827.001.0001

Czerniak, Julia. Formerly Urban: Projecting Rustbelt Futures. New York, NY: Princeton Architectural Press, 2013.

Duca, Lauren. "The Miley Cyrus Twerking Backlash. HuffPost. Posted August 2013. http://www.huffingtonpost.com/2013/08/28/miley-cyrus-twerking_n_3830560.html 
Gamp, Joe. "Lemonade and Minute Maid: Taylor Swift Accused of Copying Beyonce in Look What You Do," Metro UK 8/2016 http://metro.co.uk/2017/08/26/lemonade-andminute-maid-taylor-swift-accused-of-copying-beyonce-in-look-what-you-made-medo-teaser-6880300/

Hagan, Cara. "Visual Politics in American Dance Film: Representation and Disparity" International Journal of Screendance 8 (2017).

https://doi.org/10.18061/ijsd.v8i0.5360

Harge, Jennifer and Ryan Kerr. "Listen," 2016.

https://www.youtube.com/watch?v=leX66EpWyY0

Hoch, Danny. "Towards a Hip-Hop Aesthetic: A Manifesto for the Hip-Hop Arts Movement," Total Chaos: The Art and Aesthetics of Hip-Hop. New York, NY: Perseus Books, 9/2006. 349-361.

hooks, bell. "Homeplace: A Site of Resistance," Yearning: Race, Gender, and Cultural Politics. London, UK: Routledge, 1990. 45-53.

Indigenous Enterprise. “Untitled," 2017. https://www.youtube.com/watch?v=p1kW97Wbxg\&feature=youtu.be

Lawrence, Tim. 'Listen, and You Will Hear all the Houses that Walked There Before': A History of Drag Balls, Houses and the Culture of Voguing. London: Soul Jazz, 2011. http://www.timlawrence.info/articles2/2013/7/16/listen-and-you-will-hear-all-thehouses-that-walked-there-before-a-history-of-drag-balls-houses-and-the-culture-ofvoguing

Leuthold, Steven. Indigenous Aesthetics: Native Art, Media, and Identity. Austin, TX: University of Texas Press. 1998.

McKee, Robert. Story: Style, Structure, Substance, and the Principles of Screenwriting. New York, NY: HarperCollins Books, 1997.

Ortiz, Paul. An African-American and Latinx History of the US. Boston, MA: Beacon Press, 1996.

Rosenberg, Douglas. "Excavating Genre," Screendance: Inscribing the Ephemeral Image. Oxford University Press, 2012. 110-124. https://doi.org/10.1093/acprof:oso/9780199772612.001.0001

Said, Edward. Orientalism. London, UK: Penguin Classics, 1979.

Santiago, Charlene. "Transgender and Undocumented Leader Fights for Rights," Cronkite News, April 27 2017. https://cronkitenews.azpbs.org/2017/04/27/62749/ 
Smith, Mitch "Minnesota Officer Acquitted in Killing of Philando Castile" New York Times, June 2017. https://www.nytimes.com/2017/06/16/us/police-shooting-trialphilando-castile.html.

Sugrue, Thomas. The Origins of Urban Crisis: Race and Inequality in Postwar Detroit. Princeton, NJ: Princeton University Press, 1998.

“Drug Dealers, Criminals, Rapists: What Trump Thinks of Mexicans." BBC News. Posted August 2016. http://www.bbc.com/news/av/world-us-canada-37230916/drug-dealerscriminals-rapists-what-trump-thinks-of-mexicans 